\title{
Toegevoegde waarde in jaarverslae van Suid-Afrikaanse maatskappye: 'n Kort oorsig van die praktyk
}

\author{
A.P. du Plessis \\ Departement Bedryfsekonomie, Universiteit Vista, Privaatsak X613, Port Elizabeth, 6000 Republiek van Suid-Afrika
}

Aanvaar 29 Junie 1987

\begin{abstract}
South African listed companies (Johannesburg Stock Exchange, Industrial) have been following the example of British Companies since 1977 in the inclusion of a value-added statement in the annual report. An analysis of the statement of value added in the annual reports of 47 South African companies has shown that in respect of items like the title of the statement, the format, non-trading debits and credits, payroll costs, interest and dividends, taxation and retentions, a variety of practices are followed. The mere fact that information made available in the statement of value added is not standardized, complicates the task of interest groups such as shareholders, creditors, employees, financial analysts and others. This matter should receive the urgent attention of the Accounting Practices Board of the South African Institute of Chartered Accountants.
\end{abstract}

Suid-Afrikaanse genoteerde maatskappye (Johannesburgse Effektebeurs, Nywerheid) volg reeds sedert 1977 die voorbeeld van hulle Britse eweknieë in die insluiting van 'n staat van toegevoegde waarde in jaarverslae. 'n Ontleding van die staat van toegevoegde waarde in die jaarverslae van 47 Suid-Afrikaanse maatskappye toon egter dat ten opsigte van aspekte soos die opskrif van die staat, die formaat waarin voorgestel, niehandelskrediete en -debiete, vergoeding aan werknemers, vergoeding aan kapitaalverskaffers, die Staat se aandeel en onuitgekeerde wins, 'n verskeidenheid van praktyke gevolg word. Die feit dat inligting in die staat van toegevoegde waarde nie gestandaardiseer is nie, bemoeilik die taak van belangegroepe soos aandeelhouers, kredietverskaffers, werknemers, finansiële ontleders en ander. Hierdie toedrag van sake verdien die dringende aandag van die Rekeningkundige Praktykekomitee van die Suid-Afrikaanse Instituut van Geoktrooieerde Rekenmeesters.

\section{Inleiding}

Sedert 1977 het die begrip toegevoegde waarde toenemend inslag gevind in die jaarverslae van SuidAfrikaanse maatskappye. Waar slegs drie maatskappye (Johannesburgse Effektebeurs, Nywerheid) in 1977 'n staat van toegevoegde waarde in hulle jaarverslae ingesluit het, het die getal in 1985 tot ongeveer 100 toegeneem. Die stimulus vir die insluiting van 'n staat van toegevoegde waarde in jaarverslae kan in alle waarskynlikheid teruggevoer word na die publikasie van 'The Corporate Report' (1975) in die Verenigde Koninkryk. In hierdie verslag wat aan die 'Accounting Standards Committee' vir kommentaar voorgelê is, is onder meer aanbeveel dat maatskappye 'n staat van toegevoegde waarde in hulle jaarverslae insluit. Volgens 'The Corporate Report' (1975: 49) is hierdie stap nodig want: 'There is evidence that the meaning and significance of profits are widely misunderstood. It is not the purpose of this report to attempt to justify the profit concept. We accept the proposition that profits are an essential part of any market economy, and that in consequence their positive and creative function should be clearly recognised and presented. But profit is only part of value added. From value added must come wages, dividends and interest, taxes and funds for new investment. The interdependence of each is made more apparent by a statement of value added.'

In Suid-Afrika het Roeloffse (1983) sowel as Gourley \& Rossler (1983) reeds op sekere praktiese probleme in verband met die bepaling van toegevoegde waarde sowel as die aanbieding daarvan in die jaarverslag gewys. Van die probleme wat onder meer deur hierdie outeurs aangehaal word, is die hantering van waardevermindering, rente, belasting, uitgestelde belasting, minderheidsbelange en nie-handelskrediete. Roeloffse sowel as Gourley \& Rossler is van mening dat die probleme slegs die hoof gebied kan word indien die staat van toegevoegde waarde gestandaardiseer word.

By 'n gebrek aan empiriese navorsing oor die werklike doel en inligtingswaarde van toegevoegde waarde soos opgeneem in jaarverslae, is dit waarskynlik nie raadsaam om te gou voorskriftelik te raak oor die wyse waarop die inligting in die staat van toegevoegde waarde gestandaardiseer moet word nie. Aan die ander kant toon 'n ontleding van state van toegevoegde waarde in jaarverslae dat uiteenlopende benaderings gevolg word en dat hierdie praktyk die taak van finansiële ontleders, aandeelhouers, ander kapitaalverskaffers, die algemene beleggerspubliek en werknemers kan bemoeilik.

Die doel van hierdie artikel is om aan die hand van gepubliseerde jaarverslae van Suid-Afrikaanse maatskappye wat op die Johannesburge Effektebeurs onder Nywerheid gelys word, die aard van die inligting in die staat van toegevoegde waarde na te gaan en daarop te wys dat in die afwesigheid van voorskrifte oor die opstelling, inligting geopenbaar word wat tot verwarring en gevolglik verkeerde afleidings aanleiding kan gee.

\section{Die versameling van die date}

Vir die doel van die studie is die jaarverslae van maatskappye wat op die Johannesburgse Effektebeurs onder Nywerheid gelys word en waarvan die jaarverslae op 31 Oktober 1986 beskikbaar was, nagegaan. Slegs maatskappye met 'n finansiëlejaareinde tussen 1 Januarie 1986 en 30 Junie 1986, is ingesluit. 
Van die maatskappye waarvan die jaarverslae op 31 Oktober 1986 beskikbaar was, kon 47 geïdentifiseer word wat wel 'n staat van toegevoegde waarde by die jaarverslag ingesluit het, of andersins inligting gepubliseer het waaruit afleidings in verband met toegevoegde waarde gemaak kan word. Hierdie 47 maatskappye se state van toegevoegde waarde is toe ontleed. As grondslag vir die ontleding is die voorbeeld soos deur 'The Corporate Report ' (1975: 50) aangehaal, gebruik. Daar is dus gepoog om die toegevoegde waarde in sewe standaardkomponente te verdeel, naamlik:

- Werknemersvergoeding

- Rente

- Dividende

- Belasting

- Waardevermindering

- Onuitgekeerde wins

- Buite-aandeelhouersbelang

Laasgenoemde komponent is nie in die standaardvoorbeeld soos deur 'The Corporate Report' aangehaal, ingesluit nie.

\section{Begripsbepaling en die inhoud van die staat van toegevoegde waarde}

Die begrip toegevoegde waarde as sodanig is geen nuwe begrip wat sy inslag vir die eerste keer in 'The Corporate Report' gevind het nie. Cox (1979: 12) wys daarop dat die begrip reeds in die agtiende eeu deur die Amerikaanse tesourie gebruik is toe pogings aangewend is om die nasionale inkome van die land te bepaal. Vir daardie doel het die tesourie toegevoegde waarde gedefinieer as die totale waarde van produksie in die volkshuishouding minus die waarde van aangekoopte grondstowwe en dienste.

Volgens 'The Corporate Report' (1975:49) word toegevoegde waarde uit die oogpunt van die individuele onderneming soos volg gedefinieer: 'sales income less materials and services purchased'. Die definisie van 'The Corporate Report' is eenvoudig en vind aansluiting by die definisie wat deur ekonome gebruik word by die bepaling van die bruto binnelandse produk. Hoewel uitgangspunte in beide definisies dieselfde is, verskil die bepaling van toegevoegde waarde vanuit 'n makro- en mikro-oogpunt - verskille waarop Cox (1979: 11-23) reeds gewys het.

In die aanbieding van 'n staat van toegevoegde waarde in 'n jaarverslag kan natuurlik verskeie metodes gevolg word wat sal afhang van die uitgangspunt van die opsteller van die staat. In 'The Corporate Report' (1975: 50) word 'n eenvoudige voorbeeld van die moontlike uitleg van 'n staat van toegevoegde waarde gegee. Ter wille van die bespreking word die voorbeeld van 'The Corporate Report' in Figuur 1 gegee.

Volgens die aangehaalde voorbeeld in Figuur 1 kan 'n staat van toegevoegde waarde volgens die aftrek- of bytelmetode opgestel word. Indien die aftrekmetode gebruik word, word toegevoegde waarde verkry deur bloot die inkomste uit verkope te verminder met die waarde van die aangekoopte grondstowwe en dienste. Die bytelmetode sommeer bloot die aanwending van

\section{A MANUFACTURING COMPANY STATEMENT OF VALUE ADDED}

\begin{tabular}{|c|c|c|c|c|}
\hline Turnover & 31 & $\begin{array}{l}\text { ear to } \\
\text { ec. } 1974 \\
\text { fM } \\
103,9\end{array}$ & & $\begin{array}{c}\text { Preceding } \\
\text { year } \\
\text { £M } \\
102,3\end{array}$ \\
\hline Bought in materials and services & & 67,6 & & 72,1 \\
\hline Volue added & & $\mathfrak{£ 3 6 , 3}$ & & $£ 30,2$ \\
\hline \multicolumn{5}{|l|}{$\begin{array}{l}\text { Applied the following way } \\
\text { To pey employees }\end{array}$} \\
\hline \multicolumn{5}{|l|}{ To pay providors of capital } \\
\hline interest on loans & 0,8 & & 0,6 & \\
\hline $\begin{array}{l}\text { dividends to shareholders } \\
\text { To pey government }\end{array}$ & 0,9 & 1,7 & 0,9 & 1,5 \\
\hline corporation tax payable & & 3,9 & & 3,1 \\
\hline \multicolumn{5}{|l|}{$\begin{array}{l}\text { To provide for maintenance and } \\
\text { expansion of assets }\end{array}$} \\
\hline depreciation & 2,0 & & 1,8 & \\
\hline \multirow[t]{2}{*}{ retained profits } & 2,8 & 4,8 & 6,5 & 8,3 \\
\hline & & $\mathfrak{f 3 6 , 3}$ & & $£ 30,2$ \\
\hline
\end{tabular}

Figuur 1 Voorbeeld van die uitleg van 'n staat van toegevoegde waarde

toegevoegde waarde onder vier hoofgroepe, te wete werknemers; kapitaalverskaffers; die Staat en waardevermindering en onuitgekeerde winste.

In die nasionale rekeninge van 'n land word tussen bruto toegevoegde waarde en netto toegevoegde waarde onderskei. In die geval van bruto toegevoegde waarde (dit is bruto binnelandse produk teen faktorkoste) is waardevermindering ingesluit, terwyl by netto toegevoegde waarde (dit is netto nasionale inkome teen faktorkoste) waardevermindering uitgesluit word. Toegepas op die voorbeeld in 'The Corporate Report' is die toegevoegde waarde wat daar aangetoon word, bruto toegevoegde waarde. Indien waardevermindering as 'n item by aangekoopte materiaal en dienste ingesluit sou word, sou die resultaat netto toegevoegde waarde wees. Oor die twee metodes van berekening van toegevoegde waarde vir die doeleindes van verslaglewering deur individuele maatskappye bestaan daar ernstige meningsverskil. (Kyk byvoorbeeld Bijl, 1982 en Morley, 1979a).

In Suid-Afrika is daar geen wetlike voorskrifte wat maatskappye verplig om 'n staat van toegevoegde waarde op te stel en te publiseer nie. Die publikasie daarvan moet dus gesien word as 'n poging om op 'n meer positiewe wyse finansiële resultate aan die onderskeie belangegroepe bekend te stel. In die afwesigheid van definitiewe voorskrifte, is een van die gevolge natuurlik dat inligting in state van toegevoegde waarde nie altyd op 'n konsekwente en verstaanbare wyse gerapporteer word nie. 


\section{Empiriese bevindings}

Die empiriese bevindings sal onder die volgende hoofde bespreek word: Opskrif van die staat; Formaat waarin voorgestel; Nie-handelskrediete en -debiete; Vergoeding van werknemers; Vergoeding aan kapitaalverskaffers; Die Staat se aandeel; en Waardevermindering en onuitgekeerde wins.

\section{Opskrif van die staat}

Die meerderheid van die maatskappye in die ondersoek gebruik konvensionele benamings om die naam van die staat aan te dui. Die benaming wat die meeste voorgekom het (31 uit 47), was 'Value Added Statement'. Van die minder konvensionele benamings wat wel gebruik word, word hieronder aangedui:

'Distribution of Value Added' (P.G. Groep)

'Distribution of Revenue' (Everite)

'Wealth Creation' (Irvin \& Johnson)

'Wealth Created' (Saficon)

'Group Wealth' (Pick 'n Pay Groep)

'Value Added Analysis' (Tongaat-Hulett)

In 'n studie van die opskrifte van state van toegevoegde waarde in Brittanje, het Rutherford (1980: 16) bevind dat vir die jare $1977 / 78$ meer as $83 \%$ van die maatskappye konvensionele opskrifte soos 'Statement of Value Added', Added Value Statement', ensovoorts gebruik het.

Hoewel 'The Corporate Report' die benaming 'Statement of Value Added' in die voorbeeld gebruik het, wil dit voorkom asof die Suid-Afrikaanse maatskappye eerder die opskrif 'Value Added Statement' verkies.

\section{Formaat waarin voorgestel}

'n Analise van die jaarverslae van die 47 maatskappye wat wel 'n staat van toegevoegde waarde gepubliseer het, toon 'n interessante variasie van formate. 'n Opsomming van die belangrikste aspekte in verband met die formaat, word in Tabel 1 getoon.

Uit die gegewens in Tabel 1 is dit opmerklik dat die maatskappye aansienlike moeite doen om die staat van toegevoegde waarde op so 'n wyse voor te stel dat dit nie

Tabel 1 Uiteensetting van die belangrikste aspekte in verband met die formaat van die staat van toegevoegde waarde

\begin{tabular}{lcc}
\hline Veranderlike & $\begin{array}{c}\text { Aantal } \\
\text { maatskappye }\end{array}$ & $\begin{array}{r}\% \text { van } \\
\text { totaal }\end{array}$ \\
\hline Bytel- en aftrekmetode & 42 & 89,4 \\
Slegs bytelmetode & 3 & 6,4 \\
Ander metode & 2 & 4,2 \\
\cline { 2 - 3 } Definisie van toegevoegde waarde ingesluit & 23 & 48,9 \\
Vergelykende syfers & 38 & 80,9 \\
Verhoudingsgetalle & 39 & 83,0 \\
Aanvullende grafiese voorstellings & 30 & 63,8 \\
\hline
\end{tabular}

alleenlik aantreklik gemaak word vir die leser nie, maar addisionele inligting bevat wat die interpretasie daarvan vergemaklik.

'n Aspek wat opval ten opsigte van die formaat van die staat, is die gebruik van verhoudingsgetalle. Die mees algemene verhoudingsgetalle wat gebruik word, is waar die aandeel van elkeen van die sogenaamde deelnemers in toegevoegde waarde as 'n persentasie van die totale toegevoegde waarde uitgedruk word. Sommige maatskappye voer dié praktyk 'n stap verder en toon die persentasie toename of afname van die deelnemende groepe in vergelyking met die vorige jaar. Slegs een maatskappy het 'n produktiwiteitsindeks gepubliseer wat op grond van toegevoegdewaarde-syfers bereken word. Hierdie indeks word soos volg bereken: Die verhouding van werknemersvergoeding tot toegevoegde waarde.

Roeloffse (1983) het reeds gewys op die insluiting van toegevoegde waarde in bruikbare verhoudings in jaarverslae. Uit die betoog van Roeloffse kan afgelei word dat verhoudingsgetalle wat toegevoegde waarde as 'n teller of noemer in die verhouding insluit, van wesenlike nut kan wees. Veral van belang is die wyse waarop kapitaalintensiteit met behulp van toegevoegde waarde uit die oogpunt van die individuele bedryf gemeet kan word. Die verhouding wat volgens Roeloffse (1983: 12) uiters geskik is vir hierdie doel sien soos volg daaruit:

Vaste bates (boekwaarde) - gedefleer

Toegevoegde waarde - gedefleer

Die kapitaalintensiteitsverhouding verskaf 'n aanduiding van hoeveel vaste bates benodig word vir elke RI toegevoegde waarde wat geskep word. Met behulp van hierdie verhouding kan ' $n$ vergelyking getref word tussen die kapitaalintensitiwiteit van 'n individuele bedryf en die bedryfstak waarbinne die bedryf funksioneer. 'n Probleem wat egter verdere navorsing vereis, is dié van gedefleerde waardes wat gebruik moet word. Tensy ' $n$ instansie soos byvoorbeeld die Reserwebank bereid is om inligting in verband met deflators bekend te maak, sal die individuele onderneming dit moeilik vind om hierdie verhoudingsyfer te bereken.

\section{Nie-handelskrediete en -debiete}

In die aanbevelings van 'The Corporate Report' word geen melding gemaak van die wyse waarop nie-handelskrediete en -debiete in die staat van toegevoegde waarde hanteer moet word nie. By implikasie sou verwag kon word dat die rekeningkundiges wat normaalweg die staat van toegevoegde waarde voorberei, spoedig met aanbevelings sou volg. Vir Suid-Afrika bestaan daar tot op hede nie enige aanbevelings in hierdie verband nie.

Ten opsigte van die praktyk wat gevolg word deur Suid-Afrikaanse maatskappye wat in die ondersoek ingesluit is, blyk dit dat rekeningkundiges in hierdie verband uiteenlopende praktyke volg en dat eenstemmigheid nog geensins bereik is nie.

Vir die doel van die ondersoek is nie-handelskrediete 
en -debiete omskryf as daardie items wat nie uit die normale bedryfsaktiwiteite voortvloei nie, soos rente en dividende ontvang, winste van 'n buitengewone aard, inkomste uit verwante maatskappye, wisselkoersverliese en -winste en ander soortgelyke items.

Van die 47 maatskappye het slegs 18 maatskappye in die staat van toegevoegde waarde die item niehandelskrediete en -debiete afsonderlik getoon. Weliswaar word die benaming 'Nie-handelskrediete en -debiete' nie deur die maatskappye gebruik nie, maar die items wat as ander inkomste getoon word, sluit onder meer die volgende in: dividende ontvang; rente ontvang; aandeel in die winste van aanverwante maatskappye; ander bedryfsuitgawes; ander inkomste; verliese op vreemde valuta.

Hoewel sommige van die genoemde items wat in die staat van toegevoegde waarde van individuele maatskappye voorkom met inligting in die inkomstestaat of aantekeninge gerekonsilieer kon word, is dit ook so dat in baie gevalle 'n rekonsiliasie nie moontlik was nie. Indien die staat van toegevoegde waarde 'n bydrae kan lewer, dan moet die verband tussen items in die staat en die inkomstestaat met mekaar gerekonsilieer kan word. Word aan hierdie fundamentele vereiste nie voldoen nie, kan dit verwarring skep.

\section{Vergoeding aan werknemers}

In Suid-Afrika bestaan geen wetlike voorskrifte ten opsigte van die bekendmaking van globale vergoedingsyfers aan werknemers deur middel van die jaarverslag nie. Die feit dat sommige maatskappye wel bereid is om hierdie inligting in 'n staat van toegevoegde waarde te openbaar, moet aangeprys word.

Twee probleme wat egter na vore kom, is die volgende: Eerstens is dit nie duidelik watter items die maatskappye onder werknemersvergoeding insluit nie. Indien bedryfsvergelykings getref wil word, moet die analis seker wees dat ondernemings konsekwent is in die samestelling van hierdie pos. Sommige maatskappye volg die beleid om lopende inkomstebelastingaftrekkings uit te sluit en dit dan as 'n aparte item te toon as 'n oorbetaling aan die Staat. Prinsipieel is die benadering verkeerd, want die onderneming tree slegs as agent van die Staat op by die invordering van inkomstebelasting en die belasting vorm wel deel van die vergoedingspakket van werknemers.

'n Tweede probleem wat na vore tree, is wanneer maatskappye slegs die persentasie aandeel van werknemers in die staat van toegevoegde waarde toon en nie die absolute bedrae nie. Die ontleder van die staat van toegevoede waarde se taak word veral daardeur bemoeilik waar absolute bedrae uit die staat benodig word ten einde sekere verhoudingsgetalle te bereken. Hier word gedink aan sekere produktiwiteitsindekse. In die geval van OK Bazaars en die PG-Groep is dit byvoorbeeld nie moontlik om absolute syfers te bereken nie want slegs diagramme met persentasies word getoon sonder dat die toegevoegdewaarde-syfer geopenbaar word. In die geval van S.A. Brouerye kan die vergoeding van werknemers met behulp van die gepubliseerde persentasies wel afgelei word want die totale toegevoegde waarde word gepubliseer.

\section{Vergoeding aan kapitaalverskaffers}

Onder vergoeding aan kapitaalverskaffers word verstaan dividende aan gewone en voorkeuraandeelhouers en rente op lenings. Interessante variasies het na vore gekom uit die ontleding van die jaarverslae van die 47 maatskappye.

Eerstens hanteer maatskappye die item rente op lenings op twee maniere. Die een groep toon netto rentebetalings, dit wil sê rente betaal minus rente wat op beleggings ontvang is. Van die 47 maatskappye het ses maatskappye netto rentebetalings getoon, terwyl vyf maatskappye die inligting op so 'n wyse gepubliseer het dat daar nie vasgestel kan word of dit netto of bruto rentebetalings was nie. In die geval van een maatskappy word 'n item finansieringskoste getoon en hierby word ingesluit valutaverliese/koste van vooruitdekking, gekapitaliseerde bruikhure, uitgestelde verkoopooreenkomste en ander.

'n Tweede aspek wat na vore gekom het, was die gebruik deur sommige maatskappye om bruikhuurbetalings in te sluit by die vergoeding aan kapitaalverskaffers. Weer eens word in hierdie geval ook twee gebruike gevolg. Een groep maatskappye toon slegs betalings op finansiële bruikhure terwyl ander weer slegs betalings op bedryfsbruikhure toon. 'n Derde groep sluit betalings op beide tipes bruikhure in. Dit blyk duidelik uit die ontleding van die wyse van hantering van rente dat maatskappye geensins eenstemmigheid het oor watter items in- en uitgesluit moet word nie. Verder is dit ook nie in al die gevalle moontlik om rentebetalings (of finansieringskoste soos sommige maatskappye dit noem) in die staat van toegevoegde waarde met ooreenstemmende bedrae in die inkomstestaat en aantekeninge te rekonsilieer nie. Laasgenoemde toedrag van sake plaas 'n groot vraagteken oor die inligting in die staat van toegevoegde waarde.

'n Derde aspek is die hantering van dividendbetalings aan minderheidsaandeelhouers. In 'The Corporate Report' is daar geen aanbevelings oor die wyse waarop hierdie item gehanteer moet word nie. Die praktyk wat nou gevolg word, is dat sommige van die maatskappye die aandeel van minderheidsaandeelhouers wel afsonderlik toon terwyl ander maatskappye nie die gebruik volg nie.

\section{Die Staat se aandeel}

Ten opsigte van die bedrae wat onder hierdie item ingesluit moet word bestaan daar ook nie eenstemmigheid tussen maatskappye nie. Die wyse waarop die 47 maatskappye hierdie aspek hanteer, word in Tabel 2 uiteengesit.

Twee aspekte tree na vore uit 'n ontleding van die inligting in Tabel 2 Eerstens is daar die omvattende siening van sommige maatskappye oor wat alles ingesluit moet word by die aandeel van die Staat. Met die siening dat lopende belastingaftrekkings en verkoopsbelasting ook ingesluit moet word, kan die skrywer nie saamstem 
Tabel 2 Uiteensetting van die aanbieding van die item belasting in die staat van toegevoegde waarde

$\begin{array}{lr}\text { Toon slegs belasting op wins } & 33 \\ \text { Onvoldoende inligting in staat om afleidings te maak } \\ \text { Belasting op wins plus verkoopsbelasting } \\ \text { Belasting op wins plus verkoopsbelasting plus lopende } \\ \quad \text { belastingaftrekkings plus invoerregte } \\ \text { Belasting op wins plus aksynsregte } \\ \text { Belasting op wins plus aksynsregte plus verkoopsbelasting } \\ \text { Belasting op wins plus verkoopsbelasting plus lopende belas- } \\ \quad \text { tingaftrekkings plus eiendomsbelasting plus lisensiegelde } \\ \text { Belasting op wins minus uitgestelde belasting }\end{array}$

nie. In hierdie gevalle tree die maatskappye bloot as 'n invorderingsagent op en hou hierdie twee items geensins verband met die skepping van waarde nie. Indien ondernemings wel die aandeel van die Staat wil beklemtoon, kan die voorbeeld van Woolworths en Garlicks eerder gevolg word. Hierdie twee maatskappye publiseer ' $n$ afsonderlike staat waarin alle betalings aan die Staat getoon word - dit sluit bedrae in wat namens die Staat gevorder is.

Tweedens is daar die aangeleentheid van uitgestelde belasting. Die vraag bestaan of uitgestelde belasting tesame met belasting op wins getoon moet word en of dit tesame met onuitgekeerde wins getoon moet word. Uit 'n pragmatiese oogpunt wil dit voorkom asof uitgestelde belasting in elk geval 'n langtermynaspek is en dit meer logies sal wees om hierdie item by onuitgekeerde winste in te sluit. Rossler \& Gourley (1983: 225) se aanbeveling in hierdie verband lui soos volg: 'A credit transfer to the deferred taxation account for a period means that this tax will only be paid at some future time, if it is ever paid. Therefore, to reflect this as an amount payable to government would not be strictly true and it is suggested that the amount would be better disclosed as a separate item under the "to provide for expansion" category'. Op die oog af wil dit voorkom asof die aanbeveling van hierdie twee outeurs heelwat meriete inhou.

\section{Waardevermindering en onuitgekeerde winste}

Ten opsigte van die hantering van waardevermindering in die staat van toegevoegde waarde, bestaan daar in die rekeningkundige literatuur weliswaar min eenstemmigheid. Die aangehaalde voorbeeld in 'The Corporate Report' (1975: 50) behandel waardevermindering as 'n deel van die onuitgekeerde wins onder die opskrif: 'To provide for maintenance and expansion of assets'. In Brittanje was dit veral Morley (1979: 235) wat hierdie werkwyse skerp aangeval het, want deur waardevermindering as 'n aanwending te toon, word die toegevoegde waarde te hoog aangetoon - geen voorsiening word dus gemaak vir die 'gebruik' van die vaste bates in die skepping van waarde nie.

Afhangende van hoe waardevermindering in die staat van toegevoegde waarde hanteer word, kan daar dus tussen 'n nettometode en 'n brutometode van toegevoegde waarde onderskei word (Bijl, 1982).
Volgens die nettometode word waardevermindering ingesluit by die koste van aangekoopte materiaal en dienste, terwyl dit in die brutometode as 'n onderafdeling van toegevoegde waarde gewys word.

In die geval van die 47 Suid-Afrikaanse maatskappye onder bespreking, toon ' $n$ ontleding van die hantering van waardevermindering die volgende:

Metode wat gevolg word kan nie uit staat

van toegevoegde waarde afgelei word nie

Nettometode word gevolg

Brutometode word gevolg

In die geval van die 43 maatskappye wat die brutometode gevolg het, het die volgende aspekte ook na vore getree: Vyf maatskappye het waardevermindering by onuitgekeerde wins ingesluit en dit nie as afsonderlike item getoon nie. Twintig maatskappye het waardevermindering onder 'n gesamentlike hoof met onuitgekeerde wins getoon. Die mees algeme benaming wat vir die opskrif van die twee items gebruik word, is 'reinvested in the group'. Agtien maatskappye het die gebruik gevolg om waardevermindering as 'n item op sy eie in die staat van toegevoegde waarde toon.

Wat ook opgeval het, is dat die meeste maatskappye wat onder vergoeding aan vreemde kapitaalverskaffers die dividendbetalings aan minderheidsaandeelhouers as 'n aparte item getoon het, die onuitgekeerde gedeelte van winste wat minderheidsaandeelhouers toekom nie afsonderlik van ander onuitgekeerde winste getoon het nie. Geen verklaring vir hierdie gebruik kan gevind word nie.

\section{Samevatting}

In die voorafgaande paragrawe is op verskeie aspekte van die staat van toegevoegde waarde gewys. Een van die belangrikste aspekte is die verskillende wyses waarop maatskappye hierdie staat voorberei. Ten opsigte van die meeste aspekte bestaan daar nie eenstemmigheid tussen maatskappye oor wat ingesluit en uitgesluit behoort te word nie. Die mees voor-die-hand-liggende oplossing blyk te wees die uitreiking van 'n voorgestelde standpunt deur die Rekeningkundige Praktykekomitee van die Suid-Afrikaanse Instituut van Geoktrooieerde Rekenmeesters.

Uit die aard van die saak sal die Praktykekomitee die opstelling van die staat van toegevoegde waarde beoordeel vanuit die oogpunt van reeds bestaande en algemeen aanvaarde rekeningkundige beginsels. Daarmee kan nie fout gevind word nie. Wat egter nie uit die oog verloor moet word nie, is dat die fundamentele doel van die staat van toegevoegde waarde geleë is in die wyse waarop nuwe insigte in die winssyfer geopenbaar kan word. Uit die oogpunt van 'n werknemer wat veral waardevolle inligting uit die staat van toegevoegde waarde kan verkry, behoort die staat volgens die bytelmetode voorberei te word. 'n Verdere aspek in hierdie verband is dat die onuitgekeerdewinssyfer in die inkomstestaat met die onuitgekeerdewinssyfer in die staat van toegevoegde waarde versoenbaar moet wees.

Die staat van toegevoegde waarde het ingang gevind in die jaarverslae van Suid-Afrikaanse maatskappye. 
Maatskappye openbaar nie die rede waarom hulle wel 'n staat van toegevoegde waarde insluit nie. By implikasie moet afgelei word dat hulle dit doen ter wille van positiewe verslaglewering. Indien verslaglewering egter positief wil wees, moet die behoeftes van die gebruikers van die inligting in ag geneem word. Uit die oogpunt van die finansiële analis is die huidige gebrek aan standaardisasie ten opsigte van die items wat in-en uitgesluit word, onbevredigend. Dit behoort as waarskuwingsteken te dien dat die saak aandag moet geniet.

\section{Summany}

Since 1977 the term 'value added' has gained growing acceptance in the annual reports of South African companies. Where only three companies (Johannesburg Stock Exchange, Industrial) included a statement of value added in their annual reports in 1977, by 1985 the number had increased to approximately 100 . The stimulus for including the statement of value added in annual reports can be traced back to the publication of The Corporate Report (1975) in the United Kingdom. This report, which was submitted to the Accounting Standards Committee for comment, recommended that companies include a statement of value added in their annual reports.

In South Africa Roeloffse (1983) as well as Gourley \& Rossler (1983) has indicated certain practical problems regarding the assessment of the value added statement and its presentation in annual reports. Problems identified by these authors include, inter alia, the handling of depreciation, interest, tax, deferred tax, minority interest and non-trading debits and credits. In their opinion these problems can be countered only if the statement of value added becomes standardized.

From a survey of the annual reports of companies listed under Industrial on the Johannesburg Stock Exchange and whose financial years ended between 1 January 1986 and 30 June 1986, it was possible to identify 47 companies either with a statement of value added included in their annual report, or who have published information from which deductions could be made regarding value added. For the purpose of this analysis the following aspects were examined: title of statement; format of presentation; non-trading debits and credits; remuneration of employees; the state's share; and depreciation and retained income.

\section{Title of statement}

Most of the companies use conventional terms for their titles. The term appearing most often ( 31 out of 47 ) was 'Value Added Statement'. Less conventional terms used included: Distribution of Value added (PG Group); Distribution of Revenue (Everite); Wealth Creation (Irvin \& Johnson); Wealth Created (Saficor); Group Wealth (Pick 'n Pay Group); Value Added Analysis (Tongaat-Hulett).

\section{Format of presentation}

Forty-two of the 47 companies compiled the statement according to the subtractive method whereas only three applied the additive method. Furthermore, 23 companies included a definition of value added whilst 38 companies furnished comparative figures for the previous year. Thirty-nine of the 47 companies included ratios in the statement whilst 30 companies also included graphic presentations. The most common ratios used measured the share of each of the so-called participants in value added as a percentage of the total value added. Some companies took this practice a step further and showed the percentage increase or decrease of the participating groups in relation to the previous year.

\section{Non-trading debits and credits}

Only 18 of the 47 companies showed the item 'nontrading debits and credits' separately. In fact, the term 'non-trading debits and credits' was not used by the companies but the items indicated as other income included, inter alia, the following: dividends received; interest received; share of the profits of associated companies; other operating costs; other income; and loss on foreign exchange.

Although some of the debits and credits in the statement of value added individual companies can be reconciled with information in the income statement or in the notes to the financial statements, in many cases a reconciliation is not possible. For information contained the statement to be of any value, it should be possible to reconcile items contained therein with items in the income statement. Failure to comply with these fundamental requirements will result in confusion for the user.

\section{Remuneration of providers of capital}

Remuneration of providers of capital included dividends to ordinary and preference shareholders and interest on loans. Interesting variations became evident from the analysis of the annual reports of the 47 companies.

In the first instance, companies handled the item interest on loans in two ways. Six of the 47 companies showed nett interest payments, i.e. interest paid minus interest received on investments, whilst five companies published the information in such a manner that it was impossible to ascertain whether the interest payments were nett or gross. In the case of one company the item 'financing costs' was indicated, which included foreign exchange losses/costs of advance coverage and the cost of financing capitalized leases and suspensive sale agreements.

A second aspect which became evident was that some companies to include lease payments in the remuneration of providers of capital. Here again two practices were followed. One group of companies showed only payments on finance leases whereas others showed only payments on operating leases. A third group included payments on both types of leases. Analysis of the treatment of interest clearly indicates that companies do not agree at all as to the type of payment which should be included under this subsection. 
Furthermore, it is not always possible to reconcile interest payments/financing costs in the statement of value added with corrssponding amounts appearing in the income statement and notes thereto. Such a state of affairs causes the credibility of the information contained in the statement of value added to be questioned.

A third aspect which must be examined is the handling of dividend payments to minority shareholders. In 'The Corporate Report' there are no recommendations on the manner in which this item should be treated. In practice some companies did indeed indicate the share of minority shareholders separately while other companies did not indicate it at all.

\section{Depreciation}

Depending on how depreciation is handled in the statement of value added, one can differentiate between a nett and gross method of value added (Bijl, 1982). According to the nett method depreciation is included in the costs of bought-in materials and services, whereas it is indicated as a subsection of value added when the gross method is followed.

In the case of the 47 South African companies under review an analysis of the handling of depreciation shows the following:

Method followed cannot be deduced

from the statement of value added

Nett method is followed

Gross method is followed

In the case of the 43 companies using the gross method the following aspects became evident: Five companies included depreciation in retained income and did not show it as a separate item. Twenty companies showed depreciation and retained income under the joint heading of 'reinvested in the group'. Eighteen companies showed depreciation as an individual item in the statement of value added.

It appears from the aforegoing analysis of value added statements that companies do indeed follow different ways to prepare the statement of value added. With regard to most aspects there is little consensus between companies as to what should be included and what should be excluded. The most obvious solution seems to be for the Accounting Practices Board of the South African Institute of Chartered Accountants to come forward and state their viewpoint on the matter.

\section{Verrysings}

Bijl, T. 1982. Het toegevoegde waarde - overzicht: voegt dit overzicht waarde toe? De Accountant, nr. 1, 50-54.

Cox, B. 1979. Value Added. An appreciation for the accountant concerned with industry. London: Heinemann, 220p.

Gourley, B.M. \& Rossler, G.M. 1983. Reporting value added. Accountancy S.A., vol. 1, nr. 1, 21-25.

Morley, M.F. 1979a. The Value Added Statement. A review of its use in corporate reports. London: Gee \& Co, 150p.

Morley, M.F. 1979b. Value Added: the fashionable choice for annual reports and incentive schemes. The Accountants Magazine, June 1979, 234-236.

Roeloffse, D.E. 1983. Toegevoegde Waarde. 'n Vertroulike Tegniese Verslag voorgelê aan die Nagraadse Bestuurskool van die Universiteit van Stellenbosch. Stellenbosch, 79p.

Rossler G.M. \& Gourley, B.M. 1983. The value-added statement. Die Suid-Afrikaanse Geoktrooieerde Rekenmeester, vol. 19, nr. 8, 221-224.

Rutherford, B.A. 1980. Published Statements of Value Added: A Survey of Three Year's Experience. Account. Bus. Res., Winter 1980, 15-28.

The Accounting Standards Steering Committee. 1975. The Corporate Report. London, 103p. 